Growth of Boron-Doped Diamond Films on Gold-Coated Substrates with and without Gold Nanoparticle Formation

Peer-reviewed author version

NICLEY, Shannon; DRIJKONINGEN, Sien; POBEDINSKAS, Paulius; RAYMAKERS, Jorne; MAES, Wouter \& HAENEN, Ken (2019) Growth of Boron-Doped Diamond Films on Gold-Coated Substrates with and without Gold Nanoparticle Formation. In: CRYSTAL GROWTH \& DESIGN, 19(6), p. 3567-3575.

DOI: $10.1021 /$ acs.cgd.9b00488

Handle: http://hdl.handle.net/1942/29548 


\title{
Growth of boron doped diamond films on gold coated substrates with and without gold nanoparticle formation
}

\author{
Shannon S. Nicley, ${ }^{*, \dagger} \ddagger$ Sien Drijkoningen, ${ }^{\dagger}$ Paulius Pobedinskas, ${ }^{\dagger}$ Jorne \\ Raymakers, ${ }^{\dagger}$ Wouter Maes, ${ }^{\dagger}$ and Ken Haenen ${ }^{\dagger}$ \\ $\dagger$ Institute for Materials Research (IMO), Hasselt University, and IMOMEC, IMEC vzw, \\ Wetenschapspark 1, 3590 Diepenbeek, Belgium \\ $\ddagger$ Department of Materials, University of Oxford, Parks Road, Oxford, OX1 3PH, United \\ Kingdom \\ E-mail: shannon.nicley@gmail.com
}

\begin{abstract}
This work describes the growth of boron doped nanocrystalline diamond (B:NCD) films on gold coated substrates, and methodologies for achieving B:NCD with either smooth morphologies, or on top of gold nanoparticles (AuNPs) of varying sizes controlled by the surface pretreatment. B:NCD is deposited uniformly over approximately $1 \mathrm{~cm}^{2}$ gold-coated substrates. AuNPs of $\sim 100-500 \mathrm{~nm}$ diameter formed during microwave plasma assisted chemical vapour deposition, and these were overgrown by diamond. The size of the AuNPs under the diamond film can be increased by oxygen treatment of the surface prior to growth. AuNPs under the diamond film can be suppressed by growing a diamond nucleation layer at a lower temperature and in the presence of $\mathrm{CO}_{2}$ in a linear antenna diamond growth reactor. Keywords: Gold
\end{abstract}


nanoparticles, nanocrystalline diamond, oxygen termination, linear antenna, chemical vapour deposition

In this work, the formation of gold nanoparticles (AuNPs) under boron doped nanocrystalline diamond (B:NCD) is investigated with the aim of controlling their size and formation. AuNP formation under a diamond film is shown to be suppressed by a diamond nucleation layer grown at lower temperature in the presence of $\mathrm{CO}_{2}$ gas, and the substrate surface treatment is shown to be important for controlling the size of gold AuNPs.

Diamond is radiation hard, ${ }^{1}$ biologically inert, ${ }^{2}$ highly resistant to corrosion, and has excellent electrochemical characteristics. ${ }^{3-5}$ These properties make diamond exceptionally versatile, allowing for its use in extreme applications where no other suitable material may exist. ${ }^{6}$ Diamond can be grafted with biomolecules, ${ }^{7}$ as has already been demonstrated for biosensing and the fabrication of DNA chips. ${ }^{8-12}$ Analysis of the chemistry of diamond and biological-molecule interfaces is critical for understanding their resulting properties. Vibrational spectroscopy gives information about the nature of bonding, conformational changes, and composition, however it can be difficult or impossible on ultra-thin layers. Raman spectroscopy, for example, is unable to assess protein layers thinner than $50 \mathrm{~nm}$ on diamond. ${ }^{13,14}$ The use of diamond grown onto patterned gold substrates for Fourier-transform infrared (FTIR) spectroscopy using undoped diamond has proved to be an effective characterisation method for biomolecules on surfaces, ${ }^{13,15}$ and for glucose sensing. ${ }^{16}$ The use of insulating diamond substrates limits these FTIR analysis techniques to methods of functionalisation that do not use electrochemical grafting, which requires a conducting substrate. ${ }^{17,18}$ In addition to conducting substrates for FTIR analysis techniques, other applications for both doped and undoped diamond grown on gold substrates include corrosion and abrasion resistant mirrors for harsh environments for solar tracking ${ }^{19}$ and ultraviolet mirrors. ${ }^{20}$

The growth parameters for nanocrystalline diamond (NCD) in microwave plasma assisted chemical vapour deposition (MPACVD) resonant cavity reactors have been extensively investigated. ${ }^{21-25}$ Low temperature diamond growth (LTDG) is an area of active research 
interest, as processing at low temperatures is important for diamond growth on substrates with properties such as high thermal expansion coefficients, low melting temperatures, and high thermal diffusivities. ${ }^{26}$ Among the possible routes, including modification of deposition systems and altering the gas chemistry, surface wave plasma linear antenna (LA) deposition with oxygen-containing gasses ( $\mathrm{such}$ as $\mathrm{CO}_{2}$ ) in the gas mixture is considered to be the most promising LTDG growth process. ${ }^{27-30}$ Carbon dioxide is added to the plasma feed gas during LA growth to ensure effective etching of $\mathrm{sp}^{2}$ phases of carbon at low temperatures (320 $\left.410^{\circ} \mathrm{C}\right),{ }^{30-32}$ which has been shown to be beneficial for diamond grown in LA systems. ${ }^{33}$

The formation of AuNPs by annealing thin films of gold has been of significant recent interest $^{34,35}$ owing to the use of AuNPs as catalysts for growing nanowires ${ }^{36}$ and for plasmonic phenomena. ${ }^{37-42}$ The use of photonic nanoparticles can aid in the performance of photocatalytic chemical production, and diamond thin films with embedded silver nanoparticles have been shown to enhance optical absorption and photocatalytic activity for the reduction of $\mathrm{N}_{2}$ to $\mathrm{NH}_{3} \cdot{ }^{43}$ Arrays of AuNPs could also be used to maximise the absorption in the active layer of photovoltaic cells, where the particle size and shape are critical for precisely tuning the light scattering and trapping to maximise the performance. ${ }^{44}$

There are a number of methods that have been demonstrated for the synthesis of AuNPs. ${ }^{45,46}$ Colloidal AuNP solutions can be made through citrate reduction, ${ }^{47-49}$ and thiol-stabilised, water soluable AuNPs of various sizes can be synthesised by reduction of gold salts in the presence of thiol ligands. ${ }^{50-54}$ Physical vapour deposition methods include slow evaporation ${ }^{45}$ and selective nucleation techniques. ${ }^{55}$ Control of the distribution of NPs has been achieved using electron beam lithography mask templating, ${ }^{56}$ or with post-deposition annealing. ${ }^{57}$

Thin film annealing is the most high throughput, uncontaminated, and simple method of AuNP formation, compared to methods such as colloidal deposition, aerosol particle production, and electron beam lithography. However the diameter range of the particles obtained by thin film annealing can be broad, so better understanding and control of the factors, such as pretreatment, affecting the formation of AuNPs is needed. Analysis of the anneal- 
ing temperature and cooling rate on the crystallographic orientation of AuNPs has shown that annealing at lower temperature yields more faceted, larger particles with a wider size distribution. ${ }^{58}$ The surface orientation of the substrates appears to affect the mobility and crystal structure of AuNPs, ${ }^{59}$ however AuNPs formed on amorphous $\mathrm{SiO}_{2}$-glass substrates also show faceting, preferring the $\{111\}$ orientation. ${ }^{58}$

The formation of nanoparticles (NPs) by annealing occurs as a result of the processes of coalescence, Ostwald ripening, or as a combination of the two. Coalescence occurs when two small NPs merge into one larger one, thus reducing the total surface energy. Ostwald ripening is the most common form of NP formation for NPs that are well supported on a surface and separated in distance. ${ }^{60,61}$ In Ostwald ripening, smaller NPs lose atoms due to surface diffusion or evaporation, which then are driven by surface energy reduction to join larger NPs, making small NPs smaller and large NPs larger. Bechelany et al. studied the transformation of patterned thin Au films into AuNP arrays by annealing at temperatures from $400{ }^{\circ} \mathrm{C}$ to $1000{ }^{\circ} \mathrm{C}$ and in different gas ambients, including air, vacuum, $\mathrm{N}_{2}$, and $\mathrm{Ar} / \mathrm{H}_{2}$. They found that the annealing temperature and gas ambient controlled which NP formation mechanism was dominant for AuNP formation. ${ }^{62}$ The surface pretreatment and gas ambient are important parameters, and the oxidation of very small AuNPs has been shown to be a complicated process. ${ }^{63}$

The nucleation of diamond films on gold foil has been previously reported by Niu et al. ${ }^{64}$ however the adhesion was reported to be bad, with films that were easily delaminated. Gold has also been used as a very thin interlayer $(\sim 20 \AA)$ for the promotion of renucleation for low roughness diamond films, ${ }^{65}$ and the selective nucleation and growth on gold compared to alumina has also been reported. ${ }^{66}$ In this study, B:NCD thin films are grown over gold-coated substrates, and the morphologies are studied, demonstrating the growth of doped diamond films over continuous gold substrates. 


\section{Results and Discussion}

B:NCD was grown over gold-coated $1 \mathrm{~cm} \times 1 \mathrm{~cm}$ Corning Eagle $(\mathrm{CE})$ borosilicate glass substrates, as further described in the Methods section. Glass substrates were selected for the gold coating rather than silicon, as the low temperature $\mathrm{Si}-\mathrm{Au}$ eutectic causes undesirable diffusion of the Au layer into the Si. Boron doped diamond was grown rather than insulating, undoped diamond, as conductive diamond films allow for more versatility in the functionalisation methods of diamond surfaces, including electrochemical grafting. Samples grown in the same reactor with similar growth conditions showed boron concentrations of approximately $5 \times 10^{21} \mathrm{~cm}^{-3}$ and resistivity $(\rho)$ below $5 \mathrm{~m} \Omega \cdot \mathrm{cm} .{ }^{67,68}$ The diamond films in this study were grown at a lower temperature and at a lower growth speed, however these two effects have opposite effect on the boron incorporation, as higher growth temperature

and lower growth speed have both been shown to increase the boron concentration. ${ }^{68,69}$ As a result we expect the conductivity and resistivity to be similar to previous studies, however the precise values are not critical to the results of this work.

The gold coating extends to within $\sim 1 \mathrm{~mm}$ of the edge of the substrate, as shown in Figure 1A, and the appearance of the diamond, grown over the whole surface, is shown in Figure 1B. Atomic force microscopy (AFM) scans of the gold-coated substrate prior to any diamond growth or thermal treatment showed smooth surfaces, such as the $5 \mu \mathrm{m} \times 5 \mu \mathrm{m}$ scan shown in Figure 1C with root mean squared (RMS) roughness of $2.7 \mathrm{~nm}$.

\section{Analysis of Edge and Centre Regions}

Scanning Electron Microscope (SEM) investigation of the film morphology showed high quality NCD, with grain sizes on the order of several hundred nm, as shown in Figure 1D-E. The B:NCD grown over the gold-coated centre region of the substrate, shown in Figure 1D has a very similar morphology to the edge region without gold coating, as shown in Figure 1E. The similarity between the appearance of the NCD grown over the gold-coated centre region of 


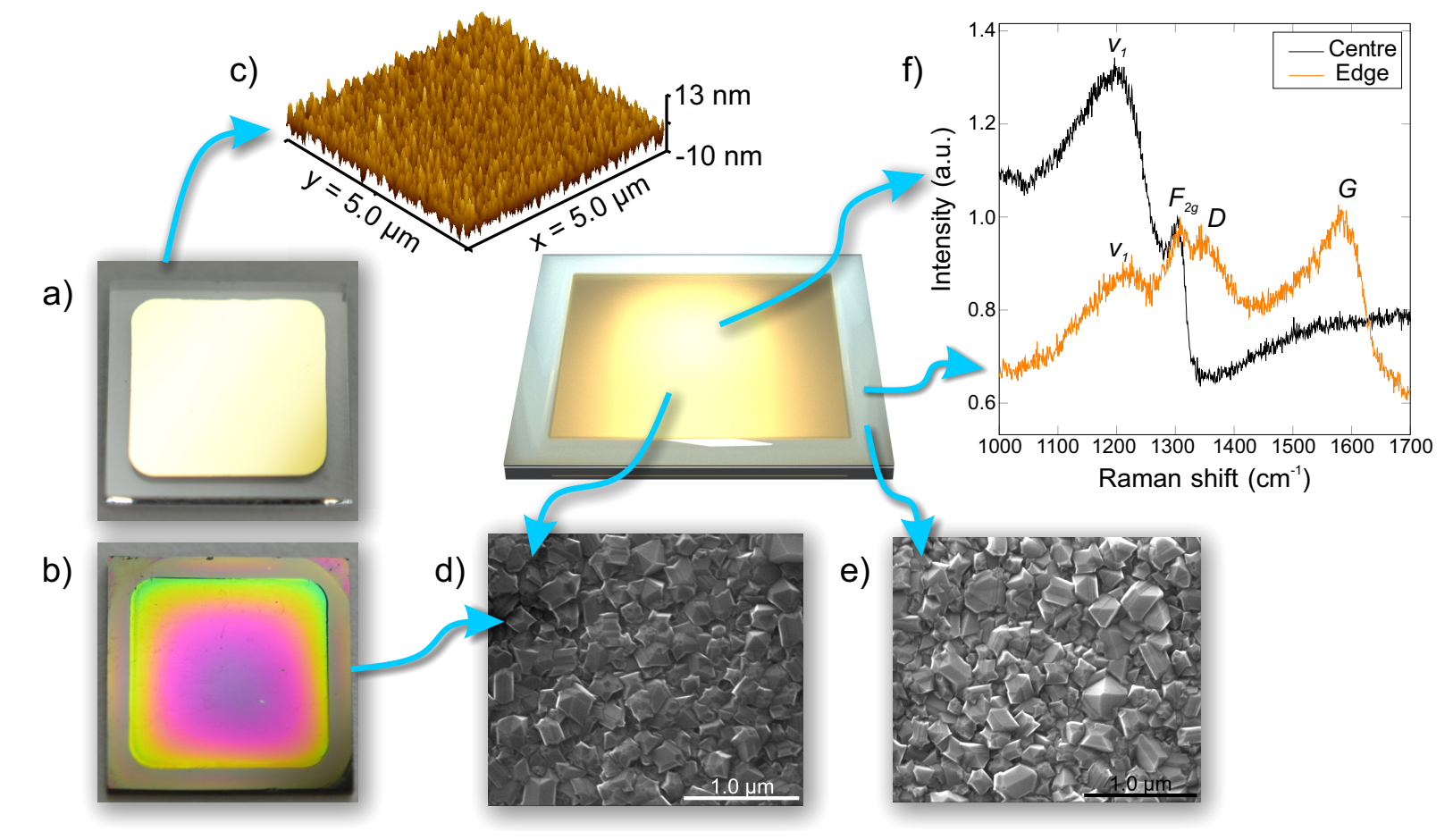

Figure 1: B:NCD on gold-coated substrates a) Macro lens camera image of a gold substrate showing the uncoated $\sim 1 \mathrm{~mm}$ edge b) B:NCD deposited on a gold-coated substrate c) AFM scan of a gold-coated substrate, as deposited before any thermal treatment or diamond growth d) SEM micrograph of NCD facets in the centre region grown over the gold-coated substrate e) SEM micrograph of NCD facets grown over the edge region without gold coating f) Representative Raman spectra of the centre and edge regions, with the intensity normalized to the $F_{2 g}$ peak. 
the substrate, compared to the edge region without gold coating, indicates that the nanoscale morphology at the diamond surface is unaffected by the presence of the gold. Raman spectroscopy was performed in two regions on the sample surface: the edge region where the B:NCD was grown directly over the glass substrate, and in the centre of the B:NCD coated gold region. Two representative spectra are given in Figure 1F. The spectra are normalised to the height of the $F_{2 g}$ (diamond) peak ${ }^{70,71}$ at $1332 \mathrm{~cm}^{-1}$. This normalisation accounts for possible differences in the measured Raman intensity due to the increased reflectivity over the gold.

There are significant differences in the Raman spectra measured on the edge and centre regions of the $\mathrm{B}: \mathrm{NCD}$ on the gold-coated substrate. Both regions show a $v_{1}$ band, at approximately $1200 \mathrm{~cm}^{-1}$. We have considered that this peak could be related to disordered diamond due to boron doping, arising from a maximum in the density of vibrational states in disordered carbon, ${ }^{72}$ or potentially from a contribution due to $\mathrm{Si}-\mathrm{O}$ stretching from the glass substrate, though the $\mathrm{Si}-\mathrm{O}$ stretching contribution is an order of magnitude lower in intensity. ${ }^{73}$ If this peak were primarily due to boron related disorder we would expect the effect to be the same both in the centre and at the edge, given that the films have a similar morphology and were grown under the same conditions, and if it were due to the glass substrate we would expect the effect to be more pronounced on the bare glass. We therefore attribute this peak, which is significantly more pronounced in the centre region over the gold-coated area, to be primarily due to a deformation mode of $\mathrm{CH}_{\mathrm{X}}$ bonds in the NCD film. ${ }^{74}$ The interaction of hydrogen with gold surfaces is not fully understood, due to the inertness of bulk $\mathrm{Au}$, however there is significant evidence for the formation of $\mathrm{Au}-\mathrm{H}$ bonds, especially on AuNPs. ${ }^{75-78}$ Previous reports have shown that the formation of $\mathrm{AuH}_{2}{ }^{-}$ and $\mathrm{AuH}_{4}{ }^{-}$on gold surfaces is stabilised by relativistic effects, ${ }^{79}$ and that $\mathrm{Au}-\mathrm{H}$ bonds are likely to form in electron-rich systems ${ }^{80}$ particularly when exposed to hydrogen plasmas. ${ }^{81}$ We therefore propose a mechanism in which $\mathrm{Au}-\mathrm{H}$ bonds form upon exposure to the hydrogen plasma, and are trapped at the interface during overgrowth. The incorporated $\mathrm{H}$ then 
has sufficient mobility in the diamond lattice to diffuse to form $\mathrm{C}-\mathrm{H}$ bonds, which are more stable under annealing. ${ }^{82}$ This process then leads to increased $\mathrm{CH}_{\mathrm{X}}$ bonds in the NCD film over the gold region as compared to the uncoated edge region.

The $\mathrm{D}$ band at $1350 \mathrm{~cm}^{-1}$ is related to disordered carbon, and the $\mathrm{G}$ band at $1588 \mathrm{~cm}^{-1}$ is related to graphite. ${ }^{83-85}$ It should be noted that the relative intensity of the $\mathrm{sp}^{3}$ and $\mathrm{sp}^{2}$ bonded carbon peaks do not imply a similar ratio within the films, since depending

on the excitation wavelength, the Raman signal can be significantly more sensitive to $\mathrm{sp}^{2}$ bonded carbon, as is the case for the $488 \mathrm{~nm}$ excitation wavelength used. ${ }^{84}$ The edge region showed considerably higher D- and G-band features in its Raman spectrum as compared to the centre. The origin of this additional $\mathrm{sp}^{2}$-content is assumed to be at the interface of the NCD and the glass substrate. An increase in graphitic content also explains the dark appearance of the edge region, as seen in Figure 1B. As this $\mathrm{sp}^{2}$-carbon enriched region does not seem to form over the gold region, its appearance is not detrimental to the formation of the diamond-coated gold structure.

\section{Formation of Gold Nanoparticles Under Diamond}

Although the nanoscale morphology of the NCD over the edge and centre regions shown in Figure 1D-E are very similar, at the microscale, the gold-coated area has bump features, as shown in Figure 2. These small $(\sim 1 \mu \mathrm{m})$ features appear only on the area of growth over the gold-coated substrate. Considering the geometry of a coated object, a bump feature with an apparent size of $1 \mu \mathrm{m}$ could be a spherical particle with a radius of $210 \mathrm{~nm}$, coated by $290 \mathrm{~nm}$ diamond.

The bumps are fairly uniformly distributed, as shown in Figure 2A, and the well faceted NCD morphology is continuous over the bump surface, as shown in Figure 2B. Energy dispersive X-ray (EDX) mapping was performed on a representative region, shown in Figure $2 \mathrm{C}$. The mapping of $\mathrm{C}, \mathrm{Au}$ and $\mathrm{Cr}$ are shown in Figure 2D-F. The distribution of gold is substantially higher in the bumps. A thin layer of Cr had been deposited to improve the gold 
a)

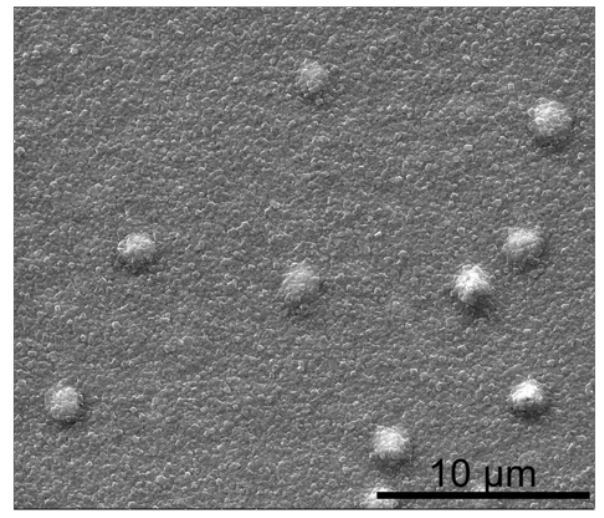

b)

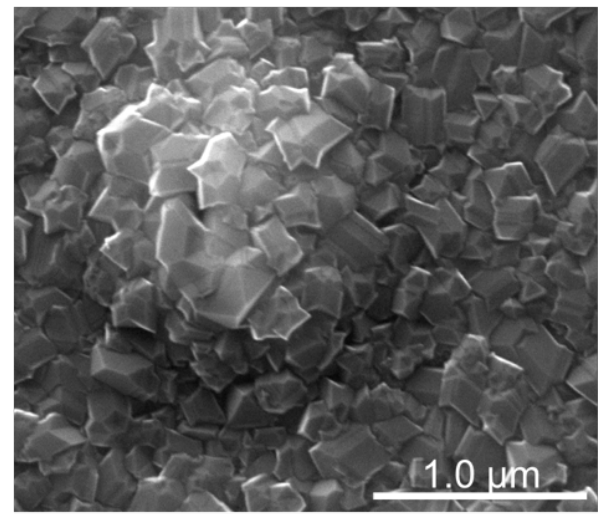

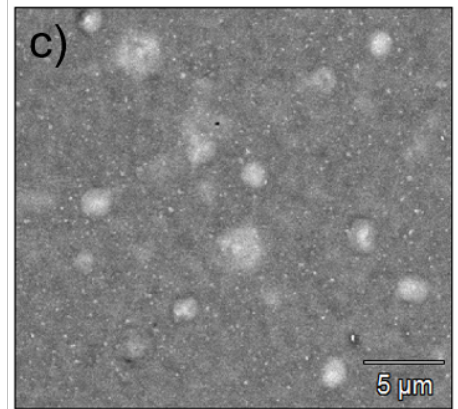
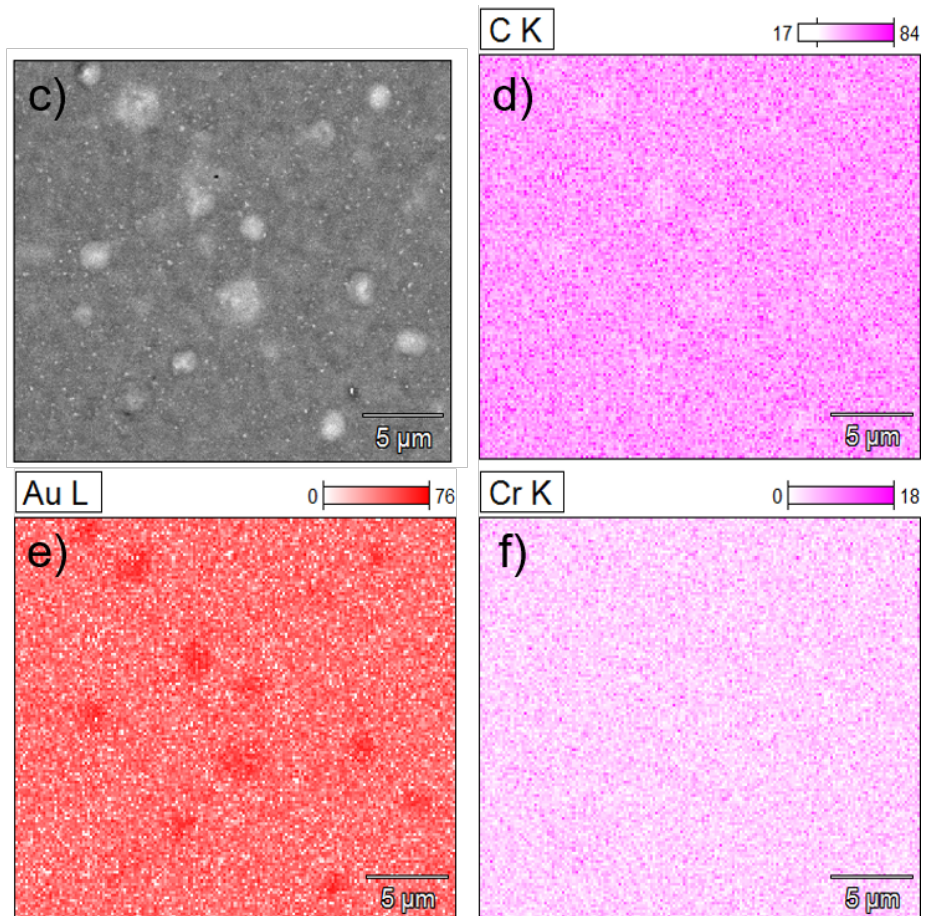

f)
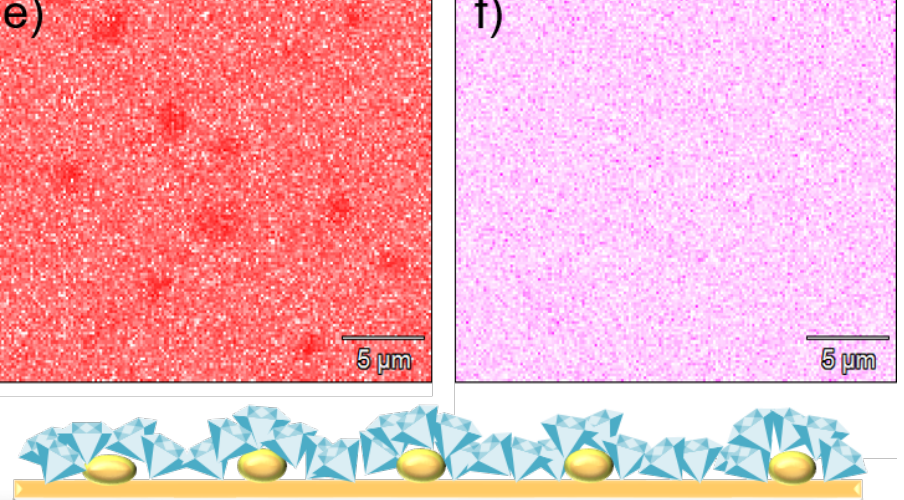

Figure 2: Diamond growth over AuNPs a) SEM micrograph in the centre region grown over the gold-coated substrate showing small bumps that form as a result of AuNP formation during thermal annealing under the diamond growth conditions b) SEM micrograph showing the NCD on the surface of these AuNP bump features have crystal facets like the surrounding surface, indicating the diamond overgrows the AuNPs. c) Backscattered electron image of a typical area in the centre region grown over the gold-coated substrate d)-f) EDX mapping of $\mathrm{C}, \mathrm{Au}$ and $\mathrm{Cr}$, respectively, of the region shown in $\mathrm{c}$ ) 
adhesion on the CE glass substrate surface, however the Cr remains uniformly distributed under the diamond surface, which indicates that the bump features are composed of gold. We therefore assign these features to be gold nanoparticles (AuNPs) which form by thermal annealing during the early stages of the diamond deposition process, and are then overgrown by diamond.

Bechelany et al. ${ }^{62}$ found that the annealing temperature controlled which NP formation mechanism was the dominant process for AuNP formation in an Ar environment, with primarily coalescence processes occurring at $400{ }^{\circ} \mathrm{C}$, and Ostwald ripening becoming more dominant through $1000^{\circ} \mathrm{C}$. They also investigated the effect of the annealing environment. Annealing in an $\mathrm{Ar} / \mathrm{H}_{2}$ gas ambient at $1000^{\circ} \mathrm{C}$ (rather than in an inert $\mathrm{Ar}$ or $\mathrm{N}_{2}$ atmosphere) suppresses Ostwald ripening, which is dominant at the same temperature in the inert atmosphere. Bechelany et al. speculated that this was due to the effect of significantly fewer metal-oxygen bonds in the reducing atmosphere. In this work, gold films are exposed to a predominantly $\mathrm{H}_{2}$ plasma environment at approximately $450-500{ }^{\circ} \mathrm{C}$. Based on the the results of Bechelany et al., we therefore expect that coalescence is still an important process at this substrate temperature, and that the effect of Ostwald ripening should be suppressed by the presence of the $\mathrm{H}_{2}$ reducing environment.

SEM investigation of the region at the boundary between the gold-coated and uncoated substrate regions shows a large interfacial region between the coated centre of the substrate on the left side of Figure 3A, and the uncoated edge region, shown on the right. As expected, the AuNP features occur only on the gold-coated region. The AuNPs within a few tens of $\mu \mathrm{m}$ of this boundary are not all completely covered by the overgrown diamond layer, as shown in Figure 3B. These AuNPs are perhaps not covered due to the longer diamond growth duration required to form a cohesive film from the top of the gold covered substrate area down to the uncoated glass region below, and this additional time before the cohesive film forms gives these AuNPs the chance to evolve to a sufficiently large height as to remain uncoated during the subsequent deposition. EDX spectroscopy performed on similar uncovered, faceted NPs 
confirmed their gold composition (Supplemental Information Figure S1). These gold particles are much larger than those which were covered during the diamond growth, which we attribute to the much longer exposure to the hydrogen plasma, as they were able to continue to evolve over the entire duration of the diamond growth. These particles are markedly faceted, as expected for approximately the temperature $\left(424^{\circ} \mathrm{C}\right)$ Kracker et al. found gave the most faceted AuNPs in their annealing experiments. ${ }^{58}$ At higher temperatures $\left(965{ }^{\circ} \mathrm{C}\right)$ they observed that the AuNPs formed rounded shapes, and concluded that a faceted texture formation is caused by self organisation during dewetting, which does not occur during the solidification process following melting. The formation of the highly faceted AuNPs shown in Figure 3B gives support to the conclusion that the facets form during dewetting, and further shows that the process is not hindered by the predominantly $\mathrm{H}_{2}$ plasma environment of the diamond growth processing conditions.

\section{Buckling Driven Delamination}

The process of buckling driven delamination was investigated to explain the large bubble features in the boundary region shown in Figure 3A. These features are significantly larger than AuNP features distant from the boundary region. The analysis of buckling failure mechanisms in compressed thin films can be applied to determine if the features arise from an equiaxial compressive stress state $\sigma_{0}$ due to the thermal expansion misfit of the diamond film and the gold substrate. ${ }^{86}$ As a film cools over a change in temperature $\Delta T=\left(T_{g}-T_{R T}\right)$ where $T_{g}$ is the growth temperature and $T_{R T}$ is room temperature, the film and substrate contract according to their coefficients of thermal expansion, $\alpha_{1}$ and $\alpha_{2}$. A compressive stress develops due to $\Delta \alpha=\alpha_{2}-\alpha_{1}$, given by,

$$
\sigma_{0}=E \Delta \alpha \Delta T /(1-\nu)
$$


where $E$ is the Young's modulus and $\nu$ is the Poisson ratio of the film. Assuming the reasonable values $^{87}$ of $E=1220 \mathrm{GPa}, \nu=0.2$, and $\Delta \alpha=13 \times 10^{-6} \mathrm{~K}^{-1}$, for a growth temperature $T_{G}=500{ }^{\circ} \mathrm{C}$ gives a compressive stress of $\sigma_{0}=9.46 \mathrm{GPa}$. It should be noted that this is significantly lower than the approximately $17 \mathrm{GPa}$ that it is estimated can be accommodated by diamond films before delamination occurs (for $\sim 1 \mu \mathrm{m}$ thick undoped polycrystalline diamond films). ${ }^{88}$

The formation of buckling features can also be analysed by considering a buckling index, ${ }^{86}$ defined as,

$$
\Pi=\left(1-\nu^{2}\right)\left(\sigma_{0} / E\right)(L / h)^{2}
$$

where $h$ is the film thickness, and $L$ is the diameter of a buckling separation. The relationship of eq. (2) can be solved to determine the diameter of a delamination at the onset of buckling, $L_{b}$. The buckling index is set equal to the critical buckling index required to initiate a circular buckle, $\Pi=\Pi_{c}=4.89 .{ }^{86}$ For the measured thickness of $h=290 \mathrm{~nm}$ and the parameters given above, this gives $L_{b}=7.5 \mu \mathrm{m}$ (which we note is much larger than the AuNPs shown in Figure 2, and therefore the AuNPs bumps could not alternatively be attributed to buckling delamination). This process gives a good explanation for the larger bubble features shown in Figure 3A, and we therefore assign these features observed at the edge of the gold region to delamination. As these features form only in the region at the edge of the gold coated region, it is also possible that the buckling delaminations form only over a region coated by chromium or without coating over the bare glass.

\section{UV-ozone Treatment Before Growth}

To investigate the effect of oxygen-metal bonds on the AuNP formation, a $290 \mathrm{~nm}$ B:NCD film was grown on a $\mathrm{A} / \mathrm{u} / \mathrm{Cr}$ coated substrate that was pretreated with $1 \mathrm{hr}$ UV-ozone

exposure before growth, as gold surfaces are known to oxidise when exposed to ozone. ${ }^{89-91}$ The resulting morphology after the UV-ozone treatment was then compared to the untreated 

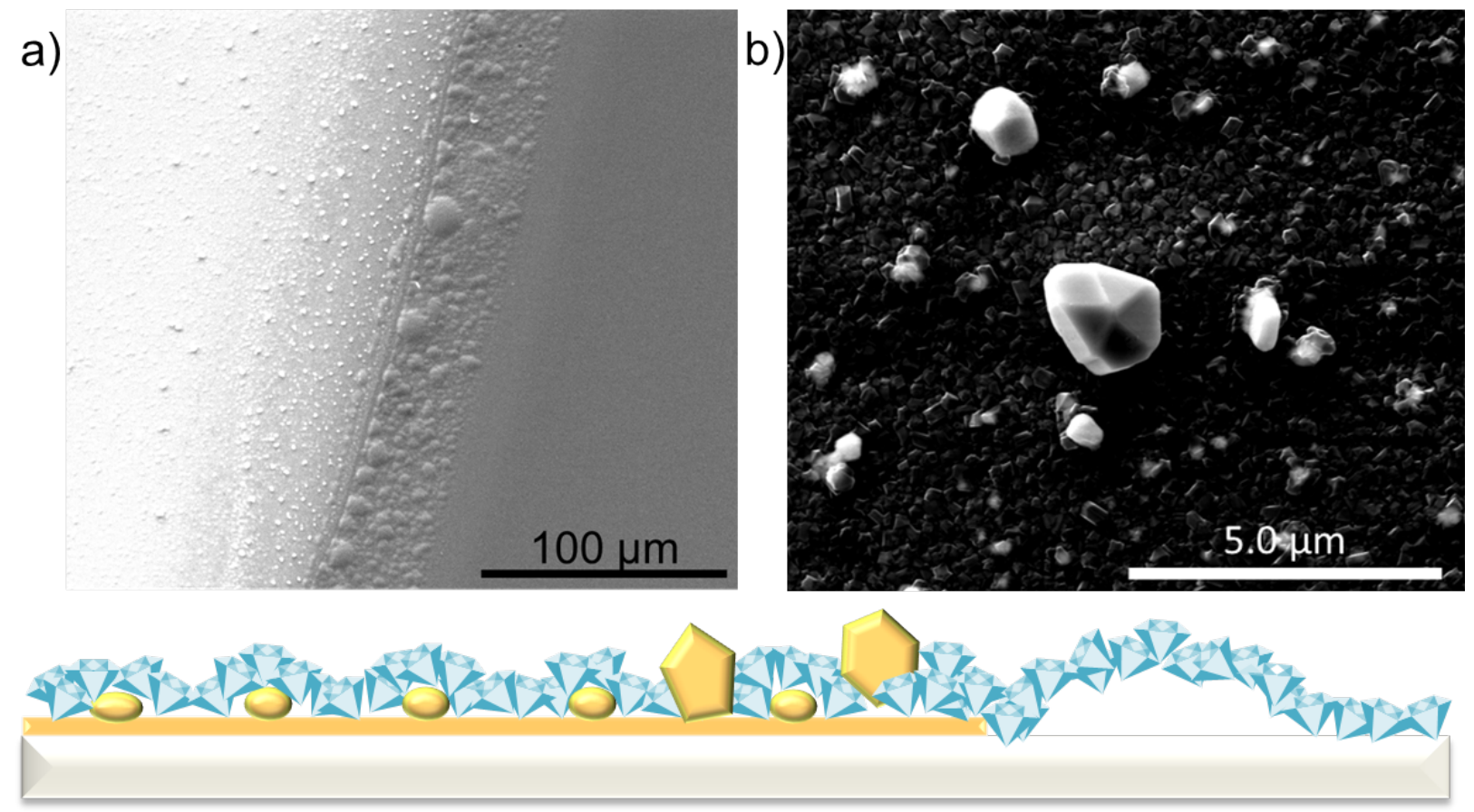

Figure 3: Morphology at the edge of the gold region. a) SEM micrograph with the goldcoated, lighter region on the left. There is a transition region in the middle with large bump features caused by buckling delamination, and the uncoated glass substrate region on the right of the image shows no AuNP features. b) SEM micrograph of larger AuNPs that form only near the edge of the gold region. Some of the AuNPs remain uncoated by diamond and show well defined crystalline faceting 
case, as shown in Figure 4. Compared to the untreated case, the UV-ozone treated sample shows larger sized AuNP formation. This indicates that oxygen surface pretreatment plays a critical role in controlling the size of the AuNPs. ${ }^{61,62}$ That the UV-ozone treatment increases the size of the AuNPs supports the conclusions of Bechelany et al., that the presence of oxygen-metal bonds makes Ostwald ripening the dominant AuNP formation method, which results in a distribution of particles skewed toward larger NPs. Further, these results indicate that this process is not only affected by the annealing ambient, but also by the surface pretreatment.
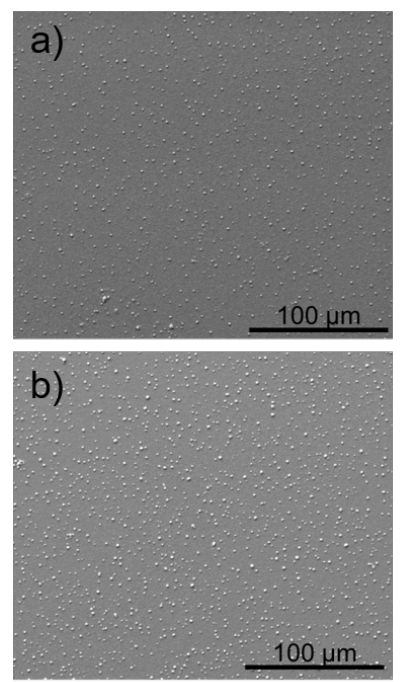
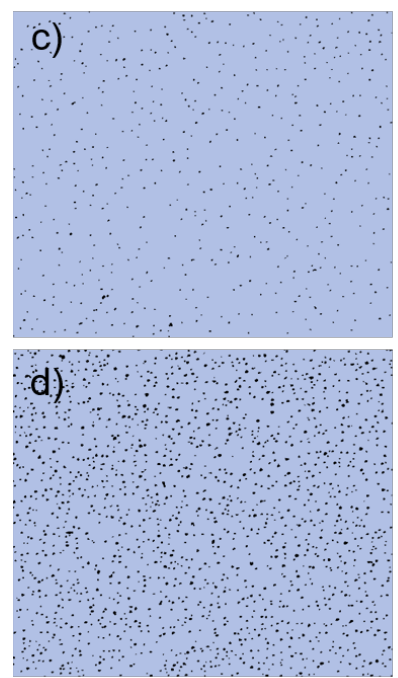
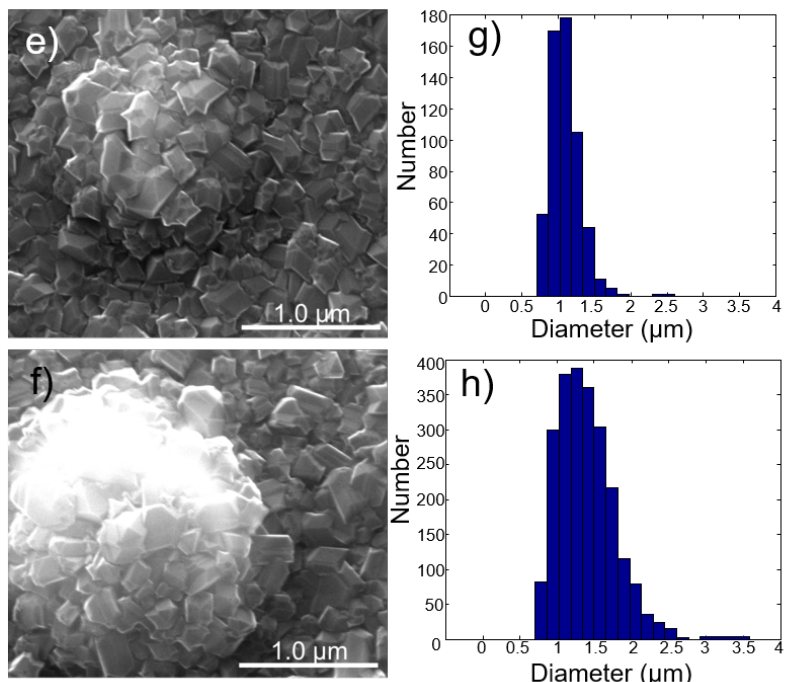

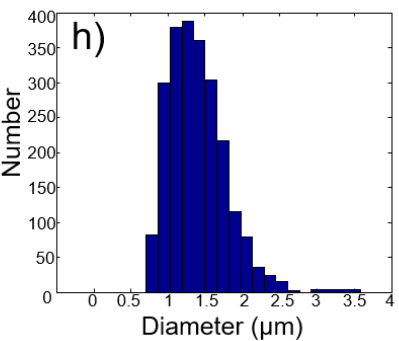

Figure 4: Oxygen treatment and AuNP particle size a)-b): SEM micrographs of representative regions over the gold-coated centre for a) $\mathrm{Au} / \mathrm{Cr}$ surface untreated before standard seeding and growth and b) Au/Cr substrate treated for $1 \mathrm{hr}$ in UV-ozone. c)-d): mapping of the AuNPs from image thresholding c) from the image of a), the untreated substrate and d) from b), the UV-ozone treated substrate. e)-f): SEM micrographs of representative coated AuNPs from e) the untreated substrate and f) UV-ozone treated substrate. g)-h): histograms of the apparent particle diameters obtained from the threshold mappings g) from the mapping in c), the untreated substrate and h) from the mapping in $d$ ) the UV-ozone treated substrate

\section{Linear Antenna Nucleation Layer}

To further explore the factors affecting formation of AuNPs, growth in a linear antenna diamond reactor at a lower deposition temperature and in the presence of $\mathrm{CO}_{2}$ was explored. 
As the linear antenna reactor set-up did not include boron-containing gas, a $70 \mathrm{~nm}$ undoped diamond nucleation layer was grown, and then a conductive layer was grown over the top using the same conditions as for the previous samples in the conventional microwave plasma (MWP) reactor. The presence of the undoped diamond layer is not expected to be problematic for applications such as the characterisation of diamond surfaces functionalised by electrochemical grafting, as the insulating glass substrate requires that the electronic contacts are made to the top surface of the diamond, which in this architecture remains the conductive boron doped layer.

The morphology of the $70 \mathrm{~nm}$ nucleation layer over the gold coated region of the substrate is shown in Figure 5A. This nucleation layer shows the presence of diamond plates, as has been previously observed for similar deposition conditions,${ }^{30}$ and no evidence of AuNP formation. The B:NCD layer was then grown over the LA nucleation layer. The overgrown layer remained smooth, with no AuNP formation. We attribute the absence of AuNPs to the lower growth temperature in the LA system and the presence of $\mathrm{CO}_{2}$ in the feed gas. The $\mathrm{CO}_{2}$ promotes oxygen-metal bonds which suppress the coalescence process, and the low temperature suppresses the Ostwald ripening, effectively preventing both processes of AuNP formation.

The edge region also smoothly transitioned from the gold to the uncoated regions of the substrate, as shown in Figure 5B. The compressive stress in the film for a growth temperature $T_{G}=370^{\circ} \mathrm{C}$ in eq. (1), gives $\sigma_{0}=6.88 \mathrm{GPa}$, only $73 \%$ of the $\sigma_{0}=9.46 \mathrm{GPa}$ obtained for the case of $T_{G}=500^{\circ} \mathrm{C}$. We attribute the lack of buckling at the edge region to this lower $\sigma_{0}$, which can be accommodated without initiating buckling, even in the edge region. We assume that $\Delta \alpha$ between the doped diamond layer and the undoped nucleation layer is negligibly small, and therefore the doped layer also shows no buckling, even following the higher temperature deposition. 


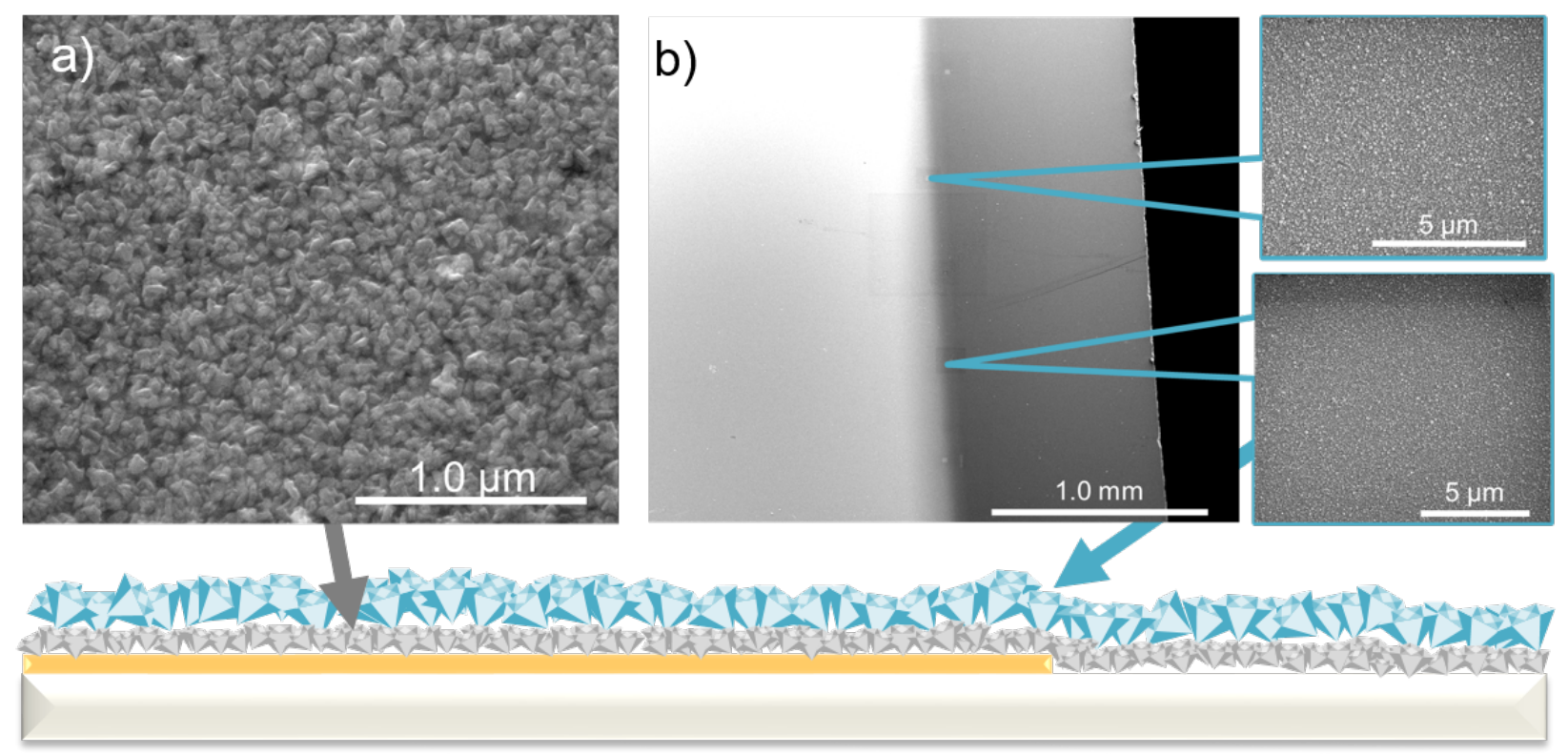

Figure 5: Linear Antenna Nucleation Layer a) SEM micrograph showing the morphology of the $70 \mathrm{~nm}$ thick diamond nucleation layer grown in the linear antenna reactor b) SEM micrograph of the region at the edge of the gold-coated and uncoated regions. The callout images show the morphology at the indicated positions on the gold edge showing the continuous diamond film morphology even across the coated and uncoated boundary region

\section{Conclusion}

We have grown boron doped diamond on $1 \mathrm{~cm}^{2}$ gold-coated substrates, and demonstrated control over the formation and size of AuNPs overgrown by the diamond layer. The diamond grown over the gold-coated region has a higher H-concentration than the uncoated edge region, and the edge region shows higher $\mathrm{sp}^{2}$ content. For $290 \mathrm{~nm}$ diamond film growth in a conventional MW reactor, AuNPs form and are overgrown by diamond. The UVozone treated substrate showed larger AuNPs than untreated substrates, which we attribute to the role of metal-oxygen bonds in promoting Ostwald ripening during the dewetting process, resulting in a distribution of particle sizes skewed toward larger particles. AuNPs at the boundary between the gold-coated and uncoated substrate regions were not completely covered by the diamond layer, and showed marked faceting, consistent with formation by long, low-temperature annealing in a reducing atmosphere. The formation of AuNPs can be suppressed completely by growing a nucleation layer of diamond in a LA reactor prior 
to B:NCD deposition, due to the suppression of both the Otswald ripening and coalescence mechanisms in this growth environment. These results represent an increased understanding of the factors affecting AuNP formation, and we have demonstrated the growth of smooth boron doped diamond layers on gold coated substrates without AuNPs. This work will allow for the synthesis of B:NCD on gold films which are useful for, among other applications, characterisation of electrochemically grafted diamond surfaces. Furthermore, we expect that the results of this study will inform future work on the optimisation of AuNP formation.

\section{Methods}

$1 \mathrm{~cm} \times 1 \mathrm{~cm}$ borosilicate glass substrates (Corning Eagle 2000) were cleaned using an RCA1 clean $\left(5: 1: 1-\mathrm{H}_{2} \mathrm{O}: \mathrm{NH}_{3}: \mathrm{H}_{2} \mathrm{O}_{2}\right.$ at $80^{\circ} \mathrm{C}$ for $\left.10 \mathrm{~min}\right)$, flushed with millipore filtered deionized (DI) water, and then cleaned with an RCA2 clean $\left(6: 1: 1-\mathrm{H}_{2} \mathrm{O}: \mathrm{HCl}_{2} \mathrm{H}_{2} \mathrm{O}_{2}\right.$ at $80{ }^{\circ} \mathrm{C}$ for 10 min). The samples were rinsed with DI water and dried with nitrogen before they were

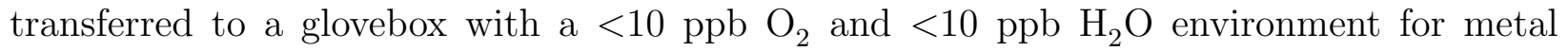
deposition.

Thermal evaporation was performed with a shadow mask covering the outer $1 \mathrm{~mm}$ rim of the substrate. A $30 \mathrm{~nm}$ layer of $\mathrm{Cr}$ is deposited to improve adhesion. $100 \mathrm{~nm} \mathrm{Au}$ was then deposited without breaking vacuum, forming the gold-coated substrate. The samples were removed from the glovebox environment following the metal deposition. The appearance of a gold-coated substrate is shown in Figure 1(a).

UV-ozone treatment was performed using a Benchtop UV-ozone Cleaner (Novascan, PSDUV) for $1 \mathrm{hr}$. The cleaner chamber was pumped for 10 min to evacuate the ozone after the treatment and then the sample was immediately diamond seeded and loaded into the growth reactor.

Seeding of the substrates prior to diamond deposition is done with a colloidal suspension of detonation nanodiamonds $6-7 \mathrm{~nm}$ in size (NanoCarbon Institute Co., Ltd.) with a zeta 
potential of $(45 \pm 5) \mathrm{mV}$, diluted in water to a concentration of $0.33 \mathrm{~g} \mathrm{~L}^{-1}$. The seeding solution is drop-cast and then spun at $4000 \mathrm{rpm}$ on a commercially available spin coater (WS-400B-6NPP/LITE, Laurell Technologies Co.). The sample is rinsed continuously with deionized water during the first 20 s of spinning, and then allowed to spin-dry.

The growth of an undoped diamond nucleation layer was performed in an LA CVD system. ${ }^{30}$ The plasma feedgas was $5 \%$ methane and $6 \% \mathrm{CO}_{2}$ in hydrogen, and the microwave power and pressure were $2.4 \mathrm{~kW}$ and 0.21 mbar, respectively. The film thickness was monitored by in situ laser reflection interferometry and stopped when the desired $70 \mathrm{~nm}$ film thickness was reached. The substrate temperature during growth was $370^{\circ} \mathrm{C}$, without any external heating applied.

B:NCD is deposited by MWP assisted chemical vapour deposition (CVD) in a $2.45 \mathrm{GHz}$ microwave power supply reactor (6500 series, ASTEX). The vacuum chamber was pumped down prior to deposition by turbomolecular pump to a base pressure of $<5 \times 10^{-6} \mathrm{mbar}$. The forward power was set to $2300 \mathrm{~W}$, and the working pressure was held at 11 Torr. The total flow rate of the predominantly $\mathrm{H}_{2}$ process gas was $500 \mathrm{sccm}$, with a $1 \% \mathrm{CH}_{4}$ concentration and a TMB $/ \mathrm{CH}_{4}$ ratio of $20,000 \mathrm{ppm}(2 \%)$. The substrate to plasma distance was estimated to be less than $1 \mathrm{~mm}$. The temperature during growth was assessed by an infrared pyrometer (Cyclops 52, Minolta), however the growth temperature, measured at $450-500{ }^{\circ} \mathrm{C}$, was below the recommended range for the instrument, and is therefore an estimated value. The thickness of grown films was determined in situ by observing the interference fringes of a $405 \mathrm{~nm}$ laser, and the deposition over the continuous gold substrate was stopped after $19 \mathrm{~h}$ at a thickness of $290 \mathrm{~nm}$.

Micro-Raman spectroscopy (T64000, Horiba Jobin-Yuan) was carried out over the range of $100-2200 \mathrm{~cm}^{-1}$ with a confocal microscope at $100 \times$ magnification, and a $488 \mathrm{~nm}$ wavelength Ar-ion laser (SHG-95, Lexel) at $400 \mathrm{~mW}$. Scanning electron microscopy (SEM) and EDX mapping (Quanta 200F, FEI) were performed at $15 \mathrm{keV}-20 \mathrm{keV}$. AFM scans were performed on a Bruker Multimode 8 in tapping mode. 


\section{Acknowledgements}

This work was financially supported by the Hasselt University Special Research Fund (BOF) and the Methusalem NANO network. The Hercules Foundation Flanders is acknowledged for financial support of the Raman equipment. SSN is a Newton International Fellow of the Royal Society. PP is a Postdoctoral Fellow and JR is a PhD Fellow of the Research Foundation - Flanders (FWO). We gratefully acknowledge B. Rezek for fruitful discussions, and B. Ruttens and J. Baccus for technical assistance.

\section{Supporting Information Available:}

X-ray spectroscopy results of faceted gold nanoparticles at the edge of gold coated region, as described in the text, are given in the Supplementary Information. This material is available free of charge via the Internet at http://??

\section{References}

1. Kagan, H. Diamond radiation detectors may be forever! Nuclear Instruments and Methods in Physics Research Section A: Accelerators, Spectrometers, Detectors and Associated Equipment 2005, 546, 222-227.

2. Tang, L.; Tsai, C.; Gerberich, W. W.; Kruckeberg, L.; Kania, D. R. Biocompatibility of chemical-vapour-deposited diamond. Biomaterials 1995, 16, 483-488.

3. Fischer, A. E.; Show, Y.; Swain, G. M. Electrochemical performance of diamond thin-film electrodes from different commercial sources. Analytical Chemistry 2004, 76, 2553-2560.

4. Yang, N. J.; Foord, J. S.; Jiang, X. Diamond electrochemistry at the nanoscale: A review. Carbon 2016, 99, 90-110.

5. Geiger, S.; Kasian, O.; Mingers, A. M.; Nicley, S. S.; Haenen, K.; Mayrhofer, K. J. J.; Cherevko, S. Catalyst Stability Benchmarking for the Oxygen Evolution Reaction: The 
Importance of Backing Electrode Material and Dissolution in Accelerated Aging Studies. ChemSusChem 2017, 10, 4140-4143.

6. May, P. W. Diamond thin films: a 21st-century material. Philosophical Transactions of the Royal Society of London. Series A: Mathematical, Physical and Engineering Sciences 2000, 358, 473-495.

7. Härtl, A.; Schmich, E.; Garrido, J. A.; Hernando, J.; Catharino, S. C. R.; Walter, S.; Feulner, P.; Kromka, A.; Steinmüller, D.; Stutzmann, M. Protein-modified nanocrystalline diamond thin films for biosensor applications. Nature Materials 2004, 3, 736-742.

8. Yang, W.; Auciello, O.; Butler, J. E.; Cai, W.; Carlisle, J. A.; Gerbi, J. E.; Gruen, D. M.; Knickerbocker, T.; Lasseter, T. L.; Russell J.N. Smith, L. M. et al. DNA-modified nanocrystalline diamond thin-films as stable, biologically active substrates. Nature Materials 2002, 1, 253-257.

9. Yang, N.; Uetsuka, H.; Nebel, C. E. DNA-sensing with nano-textured diamond electrodes. Diamond and Related Materials 2009, 18, 592-595.

10. Takahashi, K.; Tanga, M.; Takai, O.; Okamura, H. DNA preservation using diamond chips. Diamond and Related Materials 2003, 12, 572-576.

11. Wenmackers, S.; Christiaens, P.; Daenen, M.; Haenen, K.; Nesládek, M.; van deVen, M.; Vermeeren, V.; Michiels, L.; Ameloot, M.; Wagner, P. DNA attachment to nanocrystalline diamond films. Physica Status Solidi (A) Applications and Materials Science 2005, 202, 2212-2216.

12. Cornelis, P.; Vandenryt, T.; Wackers, G.; Kellens, E.; Losada-Prez, P.; Thoelen, R.; Ceuninck, W. D.; Eersels, K.; Drijkoningen, S.; Haenen, K. et al. Heat transfer resistance as a tool to quantify hybridization efficiency of DNA on a nanocrystalline diamond surface. Diamond and Related Materials 2014, 48, 32-36. 
13. Kozak, H.; Babchenko, O.; Artemenko, A.; Ukraintsev, E.; Remes, Z.; Rezek, B.; Kromka, A. Nanostructured diamond layers enhance the infrared spectroscopy of biomolecules. Langmuir 2014, 30, 2054-2060.

14. Rezek, B.; Ukraintsev, E.; Michalkov, L.; Kromka, A.; Zemek, J.; Kalbacova, M. Adsorption of fetal bovine serum on $\mathrm{H} / \mathrm{O}$-terminated diamond studied by atomic force microscopy. Diamond and Related Materials 2009, 18, 918-922.

15. Remes, Z.; Kromka, A.; Kozak, H.; Vanecek, M.; Haenen, K.; Wenmackers, S. The infrared optical absorption spectra of the functionalized nanocrystalline diamond surface. Diamond and Related Materials 2009, 18, 772-775.

16. Zhao, W.; Xu, J.-J.; Qiu, Q.-Q.; Chen, H.-Y. Nanocrystalline diamond modified gold electrode for glucose biosensing. Biosensors and Bioelectronics 2006, 22, 649-655.

17. Uetsuka, H.; Shin, D.; Tokuda, N.; Saeki, K.; Nebel, C. E. Electrochemical grafting of boron-doped single-crystalline chemical vapor deposition diamond with nitrophenyl molecules. Langmuir 2007, 23, 3466-3472.

18. Raymakers, J.; Artemenko, A.; Nicley, S. S.; Stenclova, P.; Kromka, A.; Haenen, K.; Maes, W.; Rezek, B. Expanding the Scope of Diamond Surface Chemistry: Stille and Sonogashira Cross-Coupling Reactions. Journal of Physical Chemistry C 2017, 121, 23446-23454.

19. Feist, D. G.; Arnold, S. G.; Hase, F.; Ponge, D. Rugged optical mirrors for Fourier transform spectrometers operated in harsh environments. Atmos. Meas. Tech. 2016, 9, 2381-2391.

20. Pace, E.; Pini, A.; Corti, G.; Bogani, F.; Vinattieri, A.; Pickles, C. S. J.; Sussmann, R. CVD diamond optics for ultraviolet. Diamond and Related Materials 2001, 10, 736-743. 
21. Williams, O. A.; Daenen, M.; D’Haen, J.; Haenen, K.; Maes, J.; Moshchalkov, V. V.; Nesládek, M.; Gruen, D. M. Comparison of the growth and properties of ultrananocrystalline diamond and nanocrystalline diamond. Diamond and Related Materials 2006, $15,654-658$.

22. Williams, O. A.; Douhéret, O.; Daenen, M.; Haenen, K.; Ōsawa, E.; Takahashi, M. Enhanced diamond nucleation on monodispersed nanocrystalline diamond. Chemical Physics Letters 2007, 445, 255-258.

23. Williams, O. A.; Nesládek, M.; Daenen, M.; Michaelson, S.; Hoffman, A.; Osawa, E.; Haenen, K.; Jackman, R. B. Growth, electronic properties and applications of nanodiamond. Diamond and Related Materials 2008, 17, 1080-1088.

24. Williams, O. A. Nanocrystalline diamond. Diamond and Related Materials 2011, 20, $621-640$.

25. Gajewski, W.; Achatz, P.; Williams, O. A.; Haenen, K.; Bustarret, E.; Stutzmann, M.; Garrido, J. A. Electronic and optical properties of boron-doped nanocrystalline diamond films. Physical Review B - Condensed Matter and Materials Physics 2009, 79, 45206.

26. Izak, T.; Babchenko, O.; Potocky, S.; Remes, Z.; Kozak, H.; Verveniotis, E.; Rezek, B.; Kromka, A. In Nanodiamond; Williams, O. A., Ed.; 2014; Chapter 13, pp 290-342.

27. Kromka, A.; Babchenko, O.; Izak, T.; Hruska, K.; Rezek, B. Linear antenna microwave plasma CVD deposition of diamond films over large areas. Vacuum 2012, 86, 776-779.

28. Potocký, .; Babchenko, O.; Hruška, K.; Kromka, A. Linear antenna microwave plasma CVD diamond deposition at the edge of no-growth region of $\mathrm{C}-\mathrm{H}-\mathrm{O}$ ternary diagram. Physica Status Solidi (B) Basic Research 2012, 249, 2612-2615.

29. Mehedi, H.-A.; Achard, J.; Rats, D.; Brinza, O.; Tallaire, A.; Mille, V.; Silva, F.; Provent, C.; Gicquel, A. Low temperature and large area deposition of nanocrystalline 
diamond films with distributed antenna array microwave-plasma reactor. Diamond and Related Materials 2014, 47, 58-65.

30. Drijkoningen, S.; Pobedinskas, P.; Korneychuk, S.; Momot, A.; Balasubramaniam, Y.; Van Bael, M. K.; Turner, S.; Verbeeck, J.; Nesládek, M.; Haenen, K. On the Origin of Diamond Plates Deposited at Low Temperature. Crystal Growth 6 Design 2017, 17, 4306-4314.

31. Sun, B.; Zhang, X.; Zhang, Q.; Lin, Z. Effect of atomic hydrogen and oxygen on diamond growth. Journal of Applied Physics 1993, 73, 4614-4617.

32. Stiegler, J.; Lang, T.; Nygard-Ferguson, M.; von Kaenel, Y.; Blank, E. Low temperature limits of diamond film growth by microwave plasma-assisted CVD. Diamond and Related Materials 1996, 5, 226-230.

33. Vlček, J.; Fendrych, F.; Taylor, A.; Kratochvílová, I.; Fekete, L.; Nesládek, M.; Liehr, M. Novel Concepts for Low-pressure, Low-temperature Nanodiamond Growth Using MWlinear Antenna Plasma Sources. MRS Proceedings 2009, 1203, 05-05.

34. Wu, D.; Tang, X.; Yoon, H. S. Deposition of high-density Au nanoparticles on ITO glass by centrifugation. Journal of Nanoparticle Research 2015, 17, 184.

35. Sun, X.; Li, H. Gold nanoisland arrays by repeated deposition and post-deposition annealing for surface-enhanced Raman spectroscopy. Nanotechnology 2013, 24.

36. Messing, M. E.; Hillerich, K.; Bolinsson, J.; Storm, K.; Johansson, J.; Dick, K. A.; Deppert, K. A comparative study of the effect of gold seed particle preparation method on nanowire growth. Nano Research 2010, 3, 506-519.

37. Arnob, M. M. P.; Zhao, F.; Zeng, J.; Santos, G. M.; Li, M.; Shih, W.-C. Laser rapid thermal annealing enables tunable plasmonics in nanoporous gold nanoparticles. Nanoscale 2014, 6, 12470-12475. 
38. Clavero, C. Plasmon-induced hot-electron generation at nanoparticle/metal-oxide interfaces for photovoltaic and photocatalytic devices. Nature Photonics 2014, 8, 95-103.

39. Gonçalves, M. R. Plasmonic nanoparticles: fabrication, simulation and experiments. Journal of Physics D: Applied Physics 2014, 47, 213001.

40. Cesca, T.; Kalinic, B.; Maurizio, C.; Michieli, N.; Scian, C.; Mattei, G. Amplified sensitization of Er 3+ luminescence in silica by $\mathrm{Au} N$ quantum clusters upon annealing in a reducing atmosphere. $R S C$ Advances 2016, 6, 99376-99384.

41. Li, X. H.; Zhu, J. M.; Wei, B. Q. Hybrid nanostructures of metal/two-dimensional nanomaterials for plasmon-enhanced applications. Chemical Society Reviews 2016, 45, $3145-3187$.

42. Rais, D.; Mensik, M.; Paruzel, B.; Kurunthu, D.; Pfleger, J. Phonons spreading from laser-heated gold nanoparticle array accelerate diffusion of excitons in an underlying polythiophene thin film. Physical Chemistry Chemical Physics 2017, 19, 10562-10570.

43. Li, S.; Bandy, J. A.; Hamers, R. J. Enhanced Photocatalytic Activity of Diamond Thin Films Using Embedded Ag Nanoparticles. ACS Applied Materials \& Interfaces 2018, $10,5395-5403$.

44. Atwater, H. A.; Polman, A. Plasmonics for improved photovoltaic devices. Nature Materials 2010, 9, 205-213.

45. Hutter, E.; Pileni, M.-P. Detection of DNA Hybridization by Gold Nanoparticle Enhanced Transmission Surface Plasmon Resonance Spectroscopy. Journal of Physical Chemistry B 2003, 10\%, 6497-6499.

46. Saha, K.; Agasti, S. S.; Kim, C.; Li, X.; Rotello, V. M. Gold Nanoparticles in Chemical and Biological Sensing. Chemical Reviews 2012, 112, 2739-2779. 
47. Turkevich, J.; Stevenson, P. C.; Hillier, J. A study of the nucleation and growth processes in the synthesis of colloidal gold. Discussions of the Faraday Society 1951, 11, 55.

48. Frens, G. Controlled Nucleation for the Regulation of the Particle Size in Monodisperse Gold Suspensions. Nature Physical Science 1973, 241, 20-22.

49. Kimling, J.; Maier, M.; Okenve, B.; Kotaidis, V.; Ballot, H.; Plech, A. Turkevich Method for Gold Nanoparticle Synthesis Revisited. Journal of Physical Chemistry B 2006, 110, 15700-15707.

50. Giersig, M.; Mulvaney, P. Preparation of ordered colloid monolayers by electrophoretic deposition. Langmuir 1993, 9, 3408-3413.

51. Brust, M.; Walker, M.; Bethell, D.; Schiffrin, D. J.; Whyman, R. Synthesis of thiolderivatised gold nanoparticles in a two-phase LiquidLiquid system. J. Chem. Soc., Chem. Commun. 1994, 0, 801-802.

52. Hostetler, M. J.; Wingate, J. E.; Zhong, C.-J.; Harris, J. E.; Vachet, R. W.; Clark, M. R.; Londono, J. D.; Green, S. J.; Stokes, J. J.; Wignall, G. D. et al. Alkanethiolate Gold Cluster Molecules with Core Diameters from 1.5 to $5.2 \mathrm{~nm}$ : Core and Monolayer Properties as a Function of Core Size. Langmuir 1998, 14, 17.

53. Shon, Y.-S.; W. Peter Wuelfing, P. W.; Murray, R. W. Water-Soluble, Sulfonic AcidFunctionalized, Monolayer-Protected Nanoparticles and an Ionically Conductive Molten Salt Containing Them. Langmuir 2001, 17, 1255.

54. Lohse, S. E.; Dahl, J. A.; Hutchison, J. E. Direct Synthesis of Large Water-Soluble Functionalized Gold Nanoparticles Using Bunte Salts as Ligand Precursors. Langmuir 2010, 26, 7504-7511.

55. Cross, C. E.; Hemminger, J. C.; Penner, R. M. Physical Vapor Deposition of One- 
Dimensional Nanoparticle Arrays on Graphite: Seeding the Electrodeposition of Gold Nanowires. Langmuir 2007, 23, 10372-10379.

56. Rechberger, W.; Hohenau, A.; Leitner, A.; Krenn, J.; Lamprecht, B.; Aussenegg, F. Optical properties of two interacting gold nanoparticles. Optics Communications 2003, 220, 137-141.

57. Gaspar, D.; Pimentel, A. C.; Mateus, T.; Leitão, J. P.; Soares, J.; Falcão, B. P.; Araújo, A.; Vicente, A.; Filonovich, S. A.; Águas, H. et al. Influence of the layer thickness in plasmonic gold nanoparticles produced by thermal evaporation. Scientific Reports 2013, 3, 1469 .

58. Kracker, M.; Wisniewski, W.; Rüssel, C. Textures of Au, Pt and Pd/PdO nanoparticles thermally dewetted from thin metal layers on fused silica. RSC Advances 2014, 4, 4813548143.

59. Whiticar, A. M.; Mårtensson, E. K.; Nygård, J.; Dick, K. A.; Bolinsson, J. Annealing of $\mathrm{Au}, \mathrm{Ag}$ and $\mathrm{Au}-\mathrm{Ag}$ alloy nanoparticle arrays on GaAs (100) and (111) B. Nanotechnology 2017, 28, 205702.

60. Datye, A. K.; Xu, Q.; Kharas, K. C.; McCarty, J. M. Particle size distributions in heterogeneous catalysts: What do they tell us about the sintering mechanism? Catalysis Today 2006, 111, 59-67.

61. Plante, M. C.; Garrett, J.; Ghosh, S. C.; Kruse, P.; Schriemer, H.; Hall, T.; LaPierre, R. R. The formation of supported monodisperse Au nanoparticles by UV/ozone oxidation process. Applied Surface Science 2006, 253, 2348-2354.

62. Bechelany, M.; Maeder, X.; Riesterer, J.; Hankache, J.; Lerose, D.; Christiansen, S.; Michler, J.; Philippe, L. Synthesis Mechanisms of Organized Gold Nanoparticles: Influence of Annealing Temperature and Atmosphere. Crystal Growth $\&$ Design 2010, 10, $587-596$. 
63. Boyen, H.-G.; Kästle, G.; Weigl, F.; Koslowski, B.; Dietrich, C.; Ziemann, P.; Spatz, J. P.; Riethmüller, S.; Hartmann, C.; Möller, M. et al. Oxidation-resistant gold-55 clusters. Science (New York, N.Y.) 2002, 297, 1533-6.

64. Niu, C. M.; Tsagaropoulos, G.; Baglio, J.; Dwight, K.; Wold, A. Nucleation and growth of diamond on $\mathrm{Si}, \mathrm{Cu}$, and Au substrates. Journal of Solid State Chemistry 1991, 91, $47-56$.

65. Silva, F.; Gicquel, A.; Chiron, A.; Achard, J. Low roughness diamond films produced at temperatures less than $600^{\circ}$ C. Diamond and Related Materials 2000, 9, 1965-1970.

66. Singh, J.; Vellaikal, M.; Akhtar, M. Growth of diamond on Au (selective) and Al2O3 surfaces. Materials Science and Engineering B. 1994, 26, 41-48.

67. Janssens, S. D.; Pobedinskas, P.; Vacik, J.; Petráková, V.; Ruttens, B.; D’Haen, J.; Nesládek, M.; Haenen, K.; Wagner, P. Separation of intra- and intergranular magnetotransport properties in nanocrystalline diamond films on the metallic side of the metalinsulator transition. New Journal of Physics 2011, 13, 083008.

68. Drijkoningen, S.; Janssens, S. D.; Pobedinskas, P.; Koizumi, S.; Van Bael, M. K.; Haenen, K. The pressure sensitivity of wrinkled B-doped nanocrystalline diamond membranes. Scientific Reports 2016, 6, 35667.

69. Demlow, S. N.; Rechenberg, R.; Grotjohn, T. The effect of substrate temperature and growth rate on the doping efficiency of single crystal boron doped diamond. Diamond and Related Materials 2014, 49, 19-24.

70. Aleksenskii, A. E.; Baidakova, M. V.; Vul, A. Y.; Davydov, V. Y.; Pevtsova, Y. A. Diamond-graphite phase transition in ultradisperse-diamond clusters. Physics of the Solid State 1997, 39, 1007-1015. 
71. Osswald, S.; Mochalin, V. N.; Havel, M.; Yushin, G.; Gogotsi, Y. Phonon confinement effects in the Raman spectrum of nanodiamond. Physical Review B 2009, 80, 075419.

72. Yu, Z.-m.; Wang, J.; Wei, Q.-p.; Meng, L.-c.; Hao, S.-m.; Long, F. Preparation, characterization and electrochemical properties of boron-doped diamond films on $\mathrm{Nb}$ substrates. Transactions of Nonferrous Metals Society of China 2013, 23, 1334-1341.

73. Volodin, V.; Mortet, V.; Taylor, A.; Remes, Z.; Stuchliková, T.; Stuchlik, J. Raman scattering in boron doped nanocrystalline diamond films: Manifestation of Fano interference and phonon confinement effect. Solid State Communications 2018, 276, 33-36.

74. Mortet, V.; Zhang, L.; Eckert, M.; D’Haen, J.; Soltani, A.; Moreau, M.; Troadec, D.; Neyts, E.; De Jaeger, J.-C.; Verbeeck, J. et al. Grain size tuning of nanocrystalline chemical vapor deposited diamond by continuous electrical bias growth: Experimental and theoretical study. Physica Status Solidi (A) Applications and Materials Science 2012, 209, 1675-1682.

75. Bus, E.; van Bokhoven, J. A. Hydrogen chemisorption on supported platinum, gold, and platinumgold-alloy catalysts. Phys. Chem. Chem. Phys. 2007, 9, 2894-2902.

76. Sil, D.; Gilroy, K. D.; Niaux, A.; Boulesbaa, A.; Neretina, S.; Borguet, E. Seeing Is Believing: Hot Electron Based Gold Nanoplasmonic Optical Hydrogen Sensor. ACS Nano 2014, 8, 7755-7762.

77. Schmidbaur, H.; Raubenheimer, H. G.; Dobrzańska, L. The goldhydrogen bond, AuH, and the hydrogen bond to gold, AuHX. Chem. Soc. Rev. 2014, 43, 345-380.

78. Bakar, M. A.; Sugiuchi, M.; Iwasaki, M.; Shichibu, Y.; Konishi, K. Hydrogen bonds to $\mathrm{Au}$ atoms in coordinated gold clusters. Nature Communications 2017, 8, 576.

79. Schwerdtfeger, P.; Boyd, P. D. W.; Brienne, S.; Burrell, A. K. Relativistic Effects in Gold Chemistry. 4. Gold(III) and Gold(V) Compounds. Inorganic Chem 1992, 31, 3411-3422. 
80. Wang, X.; Andrews, L. Gold Is Noble but Gold Hydride Anions Are Stable. Angewandte Chemie International Edition 2003, 42, 5201-5206.

81. Giangregorio, M. M.; Losurdo, M.; Bianco, G. V.; Operamolla, A.; Dilonardo, E.; Sacchetti, A.; Capezzuto, P.; Babudri, F.; Bruno, G. Insight into Gold NanoparticleHydrogen Interaction: A Way To Tailor Nanoparticle Surface Charge and Self-Assembled Monolayer Chemisorption. The Journal of Physical Chemistry C 2011, 115, 1952019528.

82. Li, Y.; Jia, X.-P.; Hu, M.-H.; Liu, X.-B.; Yan, B.-M.; Zhou, Z.-X.; Zhang, Z.-F.; Ma, H.A. Growth and annealing study of hydrogen-doped single diamond crystals under high pressure and high temperature. Chinese Physics B 2012, 21, 058101.

83. Michler, J.; von Kaenel, Y.; Stiegler, J.; Blank, E. Complementary application of electron microscopy and micro-Raman spectroscopy for microstructure, stress, and bonding defect investigation of heteroepitaxial chemical vapor deposited diamond films. Journal of Applied Physics 1998, 83 .

84. Ferrari, A. C.; Robertson, J. Interpretation of Raman spectra of disordered and amorphous carbon. Physical review B 2000, 61, 14095.

85. Ferrari, A. C.; Robertson, J. Origin of the $1150 \mathrm{~cm} \$^{\wedge}\{-1\} \$$ Raman mode in nanocrystalline diamond. Physical Review B 2001, 63, 121405.

86. Hutchinson, J. W.; He, M. Y.; Evans, A. G. The influence of imperfections on the nucleation and propagation of buckling driven delaminations. Journal of the Mechanics and Physics of Solids 2000, 48, 709-734.

87. Spear, K. E.; Dismukes, J. P. Synthetic diamond: Emerging CVD science and technology; Wiley, 1994. 
88. Ager, J. W.; Drory, M. D. Quantitative measurement of residual biaxial stress by Raman spectroscopy in diamond grown on a Ti alloy by chemical vapor deposition. Physical Review B 1993, 48, 2601-2607.

89. Ron, H.; Rubinstein, I. Alkanethiol Monolayers on Preoxidized Gold. Encapsulation of Gold Oxide under an Organic Monolayer. Langmuir 1994, 10, 4566-4573.

90. King, D. E. Oxidation of gold by ultraviolet light and ozone at $25^{\circ} \mathrm{C}$. Journal of Vacuum Science $\&$ Technology A: Vacuum, Surfaces, and Films 1995, 13, 1247-1253.

91. Ron, H.; Matlis, S.; Rubinstein, I. Self-Assembled Monolayers on Oxidized Metals. 2. Gold Surface Oxidative Pretreatment, Monolayer Properties, and Depression Formation. 1998, 